\title{
RESEARCH STATUS AND DEVELOPMENT TREND OF REMOTE SENSING IN CHINA USING BIBLIOMETRIC ANALYSIS
}

\author{
Yu Zeng *, Jixian Zhang, Ruchen Niu \\ Chinese Academy of Surveying and Mapping, Beijing 100830, P.R.China - (zengyu, zhangjx, niuruch)@casm.ac.cn
}

Commission VII, WG VII/6

KEY WORDS: Remote Sensing, Bibliometrics, Citation Analysis, Highly Cited Paper, Word Frequency, Keyword, Development

\begin{abstract}
:
Remote sensing was introduced into China in 1970s and then began to flourish. At present, China has developed into a big remote sensing country, and remote sensing is increasingly playing an important role in various fields of national economic construction and social development. Based on China Academic Journals Full-text Database and China Citation Database published by China National Knowledge Infrastructure, this paper analyzed academic characteristics of 963 highly cited papers published by 16 professional and academic journals in the field of surveying and mapping from January 2010 to December 2014 in China, which include hot topics, literature authors, research institutions, and fundations. At the same time, it studied a total of 51,149 keywords published by these 16 journals during the same period. Firstly by keyword selection, keyword normalization, keyword consistency and keyword incorporation, and then by analysis of high frequency keywords, the progress and prospect of China's remote sensing technology in data acquisition, data processing and applications during the past five years were further explored and revealed. It can be seen that: highly cited paper analysis and word frequency analysis is complementary on subject progress analysis; in data acquisition phase, research focus is new civilian remote sensing satellite systems and UAV remote sensing system; research focus of data processing and analysis is multi-source information extraction and classification, laser point cloud data processing, objectoriented high resolution image analysis, SAR data and hyper-spectral image processing, etc.; development trend of remote sensing data processing is quantitative, intelligent, automated, and real-time, and the breadth and depth of remote sensing application is gradually increased; parallel computing, cloud computing and geographic conditions monitoring and census are the new research focuses to be paid attention to.
\end{abstract}

\section{INTRODUCTION}

As a macroscopic, comprehensive, and high and new technology, which can quickly obtain information of resources, environment and disasters, remote sensing was introduced into China in 1970s and then began to flourish. At present, China has developed into a big remote sensing country, and remote sensing is increasingly playing an important role in various fields of national economic construction and social development. In earlier years, some scholars stated application progress of remote sensing in China from disciplinary perspectives ( $\mathrm{Li}$ et al. 2001; Lin et al. 2011; Ning and Wang, 2014), but by using bibliometric analysis, the study of subject development and evaluation of remote sensing technology in recent years has rarely been reported. Bibliometrics is an effective and objective means to evaluate the level of scientific research, where, highly cited paper analysis and word frequency analysis are one of the important contents. Some scholars have carried out relevant research, e.g., Nie (2012) studied Chinese periodicals on orthopaedics by highly cited paper analysis; $\mathrm{Li}$ (2014) analyzed research status of chemistry in China using highly cited paper analysis; Liang and Xie(2003), Li and Yang(2004) investigated China's nanotechnology study and development of library science in China by keyword frequency analysis, respectively; Chen et al.(2013) and Ding et al.(2014) analyzed international clinical research and output of hot papers in the field of botany and zoology based on hot papers and keywords of ESI, respectively, but their keyword research was limited to hot papers. Highly cited paper analysis and word frequency analysis has different characteristics and different views. The report on research status of a subject by comprehensively using these two methods is rare.

In China, according to national standards, remote sensing is a second-grade discipline located under the first-grade discipline surveying and mapping. In order to understand the research status and development trend of remote sensing in China well, this paper proposed a method by comprehensively using highly cited paper analysis and word frequency analysis together. It analyzed academic characteristics of 6,936 highly cited papers and 51,149 keywords published by 16 professional academic journals in the field of surveying and mapping from January 2010 to December 2014, and studied periodical distribution, literature authors, research institutions as well as hot topics and development trend from the point of data acquisition, data processing and analysis, and remote sensing applications. Analysis results of this paper can provide a reference for researchers when doing scientific research. Meanwhile, it can provide a basis for editing and publishing staff when timely adjusting publishing strategy according to hot topics and research directions.

\section{DATA SOURCE AND RESEARCH METHOD}

According to latest Annual Report for Chinese Academic Journal Impact Factors (Natural Science) and Chinese S\&T Journal Citation Reports, 16 representative Chinese periodicals on surveying and mapping, and geography were selected for

\footnotetext{
* Corresponding author
} 
research. Then, based on China Academic Journals Full-text Database and China Citation Database published by China National Knowledge Infrastructure (CNKI), academic characteristics of papers in each periodical with citations greater than or equal to 10 and published from January 2010 to December 2014 were studied. Meanwhile, high frequency keywords of these 16 periodicals published during the same period were further analyzed. Data retrieval time is March, 2015. 16 periodicals used in this research are: Journal of Remote Sensing, Remote Sensing Information, Remote Sensing for Land \& Resources, Remote Sensing Technology and Application, Spacecraft Recovery \& Remote Sensing, Geo-Spatial Information Science, Geography and Geo-Information Science, Geospatial Information, Geomatics and Information Science of Wuhan University, Acta Geodaetica et Cartographica Sinica, Science of Surveying and Mapping, Bulletin of Surveying and Mapping, Journal of Geomatics Science and Technology, Engineering of Surveying and Mapping, Geomatics \& Spatial Information Technology, and Hydrographic Surveying and Chartings.

\section{ACADEMIC CHARACTERISTICS OF HOT PAPERS}

963 highly cited papers which meet the retrieval conditions were used in this research. By reading the abstracts, papers which do not belong to the field of remote sensing were excluded, and 485 papers in total were selected for analysis. The citations of 485 papers range from 10 to 69, with average citation rate 15.9 , and total citations 7701 . Where, top five highest total citations periodicals are: Remote Sensing Technology and Application, Journal of Remote Sensing, Acta Geodaetica et Cartographica Sinica, Remote Sensing for Land $\&$ Resources, and Geomatics and Information Science of Wuhan University, with total citations 1059, 964, 900, 890, and 617, respectively, and Hydrographic Surveying and Chartings has no highly cited papers in the field of remote sensing.

\subsection{Hot Topic Analysis}

By statistics of titles and abstracts of 485 papers, research focuses and development trend of remote sensing were summarized from the point of data acquisition, data processing and analysis, and remote sensing applications (Table 1).

3.1.1 Remote sensing data acquisition: With the advances of modern technology, a variety of new sensors and remote sensing platforms emerged, abilities of data acquisition significantly enhanced, and technology advancement of Chinese air-borne and space-borne remote sensing system continues to increase. In the phase of data acquisition, it can be seen that research focus is new civilian remote sensing satellite systems and UAV remote sensing system. Among highly cited papers, papers on ZY-3 satellite, HJ-1 satellite, FY-3 meteorological satellite, China-brazil earth resource satellite (CBERS), and Mapping Satellite-1, which are new civilian remote sensing satellite systems, account for $7 \%$. Where, research focuses are characteristics, correction and applications of HJ-1 satellite data, as well as imaging geometric model, geometric calibration and product precision analysis of ZY-3 satellite data. Launched in January 2012, ZY-3 satellite is the first domestic and civilian high-resolution stereo mapping satellite in China. Launched in September 2008 and November 2012, HJ-1 is the first small satellite constellation dedicated to environmental and disaster monitoring and forecasting in China, which has optical, infrared, hyper-spectral, and microwave sensors, and has the capacity of

\begin{tabular}{|c|c|c|c|}
\hline & Research theme & $\begin{array}{c}\text { Number of } \\
\text { highly cited } \\
\text { papers }\end{array}$ & Ratio \\
\hline \multirow{2}{*}{$\begin{array}{c}\text { Data } \\
\text { Acquisition }\end{array}$} & $\begin{array}{l}\text { new civilian remote } \\
\text { sensing satellite } \\
\text { systems }\end{array}$ & 34 & $7.0 \%$ \\
\hline & $\begin{array}{l}\text { UAV remote sensing } \\
\text { system }\end{array}$ & 22 & $4.5 \%$ \\
\hline \multirow{7}{*}{$\begin{array}{l}\text { Data } \\
\text { Processing } \\
\text { and } \\
\text { Analysis }\end{array}$} & $\begin{array}{l}\text { multi-source } \\
\text { information extraction } \\
\text { and classification }\end{array}$ & 92 & $19.0 \%$ \\
\hline & $\begin{array}{l}\text { laser point cloud data } \\
\text { processing }\end{array}$ & 35 & $7.2 \%$ \\
\hline & $\begin{array}{l}\text { object-oriented high } \\
\text { resolution image } \\
\text { analysis }\end{array}$ & 33 & $6.8 \%$ \\
\hline & SAR data processing & 23 & $4.7 \%$ \\
\hline & $\begin{array}{l}\text { temporal data } \\
\text { processing and change } \\
\text { detection }\end{array}$ & 22 & $4.5 \%$ \\
\hline & $\begin{array}{l}\text { multi-source image } \\
\text { registration }\end{array}$ & 20 & $4.1 \%$ \\
\hline & $\begin{array}{l}\text { fundamental physics } \\
\text { and modeling, } \\
\text { parameter inversion }\end{array}$ & 18 & $3.7 \%$ \\
\hline \multirow{3}{*}{ Applications } & $\begin{array}{l}\text { resources investigation, } \\
\text { environmental } \\
\text { protection }\end{array}$ & 23 & $4.7 \%$ \\
\hline & $\begin{array}{l}\text { integration of remote } \\
\text { sensing, GIS and GPS }\end{array}$ & 15 & $3.0 \%$ \\
\hline & $\begin{array}{l}\text { national geographic } \\
\text { conditions monitoring } \\
\text { and census }\end{array}$ & 9 & $1.9 \%$ \\
\hline
\end{tabular}

Table 1. Statistics of main research topics from 2010 to 2014

large range, all-weather, all-time and dynamic environmental and disaster monitoring. In addition, after decades of development, UAV has been developed from the research phase to the practical stage. UAV is an easy-equipped platform for light-small and simple sensors. It has the advantages of low cost, flexibility, fast response, high-resolution data acquisition, etc. Papers on UAV remote sensing system account for $4.5 \%$, and hot issues are multi-sensor integration, automatic control of sensor and technique on stabling platform, fast image processing and mosaicking, applications and prospects and so on.

3.1.2 Remote sensing data processing and analysis: With the broadening of application fields, techniques on image processing and analysis have been improved. Papers on image processing and analysis account for the largest proportion which is $64 \%$ of all highly cited papers, which implies that this part of research drew great attentions from scholars. Where, papers on multi-source information extraction and classification have the highest percentage which is $19.0 \%$. The process of information extraction and classification is the process to extract all kinds of ground features by comprehensive analysis, comparison, reasoning and judgment on various features in remote sensing images. In recent years, scholars are working on intelligent image interpretation, hoping to achieve automatic image perception and understanding which is similar to human visual system by computing technology, artificial intelligence, pattern recognition, cognitive theory, etc., and research topics are focused on simulating integrated interpretation and decision 
analysis performed by geo-science experts by computer system to visually express the inherent geo-science phenomena and geo-science process, as well as by revealing the knowledge and rules hidden in the image data and by establishment of mathematical models to extract and classify thematic information such as water, wetlands, different vegetation, buildings, land use, etc.

In image processing and analysis, the second hot research topic is laser point cloud data processing. With the emergence of full waveform analysis technology, airborne laser scanning can record more details of reflected information of surface targets, and become one of the important means for topographic survey and 3D modeling and applications. Among the highly cited papers, papers on point cloud filtering, integration of LiDAR and optical image, topographic feature extraction and model reconstruction, as well as management and rendering, filtering, segmentation and compression of terrestrial laser scanning data hold a large proportion.

Object-oriented high-resolution image analysis technique, developed in 1990s, is still a hot topic in high-resolution image processing and analysis. It emulates the human mind's cognitive powers, and renders knowledge in a semantic network, while examining pixels not in isolation, but in context. Its related papers account for $6.8 \%$, and main concerns are automatic image segmentation and effect evaluation, organization and expression of objects, image processing and classification algorithms, etc.

Other topics that draw more attentions are SAR data processing, temporal data processing and change detection, and multisource image registration. Because of many important advantages, high resolution SAR technology has gradually become an effective means for measurement of macroscopic topography, subsidence and deformation of surface, and slight variations. Chinese scholars have actively carried out relevant research on SAR image denoising, automatically matching of InSAR data, unwrapping, SAR image geometric correction, SAR image three-dimensional information extraction, deformation monitoring and change detection, and achieved remarkable results, where the relevant papers account for $4.7 \%$ of the highly cited papers. On temporal data processing and change detection, data source is becoming diversified and more change features can be detected, where radiation corrections among data become the research focus. On image registration, research focus is automatic registration technique of multisource images based on multi-baseline and multiple matching features (feature points, feature lines, etc.)

Another research direction that is paid attention to is fundamental physics and modeling, and parameter inversion. Where, couple multiple modified reflectance models and atmospheric radiative transfer model and introduce priori knowledge to improve the retrieval accuracy of land, water, air, plants and other remote sensing parameters became the recent concerns. In addition, papers on image calibration and positioning, data compression, encoding, multi-source image fusion, and teaching reform and practice are not concentrated, which count for $14 \%$ in total.

By analyzing the research theme of the highly cited papers, it can be seen that with the emergence of pattern recognition technology, computer vision technology, data mining technology and other related technologies, remote sensing data processing techniques are becoming quantitative, intelligent, automated, and real-time. Where, sparse or no control satellite image precise positioning, real-time or near real-time spaceborne/air-borne image processing technique, precise registration of multi-source or heterogeneous geospatial information, intelligent information extraction and interpretation of high-resolution imagery, imaging mechanism and fully quantitative parameter inversion, real-time and automatic change detection and hazard identification and early warning based on multi-temporal and multi-sensor data integration, as well as parallel computing and high performance computing system and methods are the development trends.

3.1.3 Remote sensing applications: Papers on remote sensing applications account for $21 \%$ of the highly cited papers. By statistics and analysis of the research themes, we can see that resources investigation and environmental protection, integration of remote sensing, GIS and GPS, as well as national geographic conditions monitoring and census are research focuses of remote sensing applications. Where, national geographic conditions monitoring and census is a new research topic and there are many hot papers on it. Investment mechanism and service model, statistics and analysis methods, establishment of monitoring indicators and standard systems, and popularization of geographic conditions monitoring have been paid more attentions to.

\subsection{Literature Author Analysis}

By statistics of the first author of 485 papers, we can see that there are 433 authors in total, where 38 authors published 2 or more than 2 highly cited papers, and 9 authors published 3 or more than 3 highly cited papers (Table 2). Academician Deren Li ranks first by publishing 6 highly cited papers, and Guo Zhang ranks second by publishing 4 highly cited papers. Authors of highly cited papers are often well-known scholars, and many articles are from domestic high level research institutes, laboratories and universities. 38 authors who published 2 or more than 2 highly cited papers account for $8.8 \%$

\begin{tabular}{|c|c|c|l|}
\hline $\begin{array}{c}\text { Author } \\
\text { Name }\end{array}$ & $\begin{array}{c}\text { Number } \\
\text { of paper } \\
\text { cited }\end{array}$ & $\begin{array}{c}\text { Total } \\
\text { Citations }\end{array}$ & \multicolumn{1}{|c|}{ Author Affiliation } \\
\hline Deren Li & 6 & 215 & $\begin{array}{l}\text { Wuhan University; State } \\
\text { Key Laboratory of } \\
\text { Information Engineering } \\
\text { in Surveying, Mapping } \\
\text { and Remote Sensing }\end{array}$ \\
\hline $\begin{array}{c}\text { Guo } \\
\text { Zhang }\end{array}$ & 4 & 45 & $\begin{array}{l}\text { State Key Laboratory of } \\
\text { Information Engineering } \\
\text { in Surveying, Mapping } \\
\text { and Remote Sensing; } \\
\text { Chinese Academy of } \\
\text { Surveying and Mapping; } \\
\text { Satellite Surveying and } \\
\text { Mapping Application } \\
\text { Center }\end{array}$ \\
\hline $\begin{array}{c}\text { Jie Chen } \\
\text { Lin }\end{array}$ & 3 & 34 & Central South University \\
\hline $\begin{array}{c}\text { Yongming } \\
\text { Xu }\end{array}$ & 3 & 33 & $\begin{array}{l}\text { Chinese Academy of } \\
\text { Surveying and Mapping }\end{array}$ \\
\hline $\begin{array}{c}\text { Huachao } \\
\text { Yang }\end{array}$ & 3 & 43 & $\begin{array}{l}\text { Nanjing University of } \\
\text { Information Science \& } \\
\text { Technology; Nanjing } \\
\text { University }\end{array}$ \\
\hline
\end{tabular}




\begin{tabular}{|l|c|c|l|}
\hline & & & $\begin{array}{l}\text { Land Environment and } \\
\text { Disaster Monitoring }\end{array}$ \\
\hline $\begin{array}{l}\text { Jingyu } \\
\text { Yang }\end{array}$ & 3 & 42 & $\begin{array}{l}\text { The PLA Information } \\
\text { Engineering University }\end{array}$ \\
\hline $\begin{array}{c}\text { Xiuxiao } \\
\text { Yuan }\end{array}$ & 3 & 42 & Wuhan University \\
\hline $\begin{array}{c}\text { Yuanfei } \\
\text { Zhang }\end{array}$ & 3 & 37 & $\begin{array}{l}\text { China Non-ferrous Metals } \\
\text { Resource Geological } \\
\text { Survey }\end{array}$ \\
\hline
\end{tabular}

Table 2. Authors of highly cited papers from 2010 to 2014

of total authors, with 89 papers published in total and total citations 1499 (19.5\% of total sample citations). It means that these authors are core researchers, accounting for $8.8 \%$ of total authors while bringing $19.5 \%$ research attentions.

\subsection{Research Institution Analysis}

485 papers involve 333 research institutions, including 5 foreign institutions. Where, 224 institutions published one highly cited paper, 20 institutions published more than 8 highly cited papers, and 13 institutions published more than 13 highly cited papers. According to statistics, average number of paper published per institution is two. From Table 3 we can see that key universities and national research institutes in China have strong research strengths, and most of them are located in Beijing. Wuhan University, Institute of Remote Sensing and Digital Earth, and University of Chinese Academy of Sciences show an obvious advantage. 13 institutions in Table 3 account for $4 \%$ of total 333 institutions while highly cited papers published accounting for $41.22 \%$ of total papers, which means that these institutions hold important places in the field of remote sensing in China and the resulted research findings have been recognized and valued.

\begin{tabular}{|c|l|c|c|}
\hline No. & \multicolumn{1}{|c|}{ Institution Name } & $\begin{array}{c}\text { Number } \\
\text { of papers }\end{array}$ & Ratio \\
\hline 1 & Wuhan University & 93 & 9.59 \\
\hline 2 & $\begin{array}{l}\text { Institute of Remote Sensing and } \\
\text { Digital Earth, Chinese Academy of } \\
\text { Sciences }\end{array}$ & 64 & 6.60 \\
\hline 3 & $\begin{array}{l}\text { University of Chinese Academy of } \\
\text { Sciences }\end{array}$ & 52 & 5.36 \\
\hline 4 & Beijing Normal University & 24 & 2.47 \\
\hline 5 & $\begin{array}{l}\text { Institute of Geographic Sciences } \\
\text { and Natural Resources Research, } \\
\text { Chinese Academy of Sciences }\end{array}$ & 23 & 2.37 \\
\hline 6 & Central South University & 23 & 2.37 \\
\hline 7 & $\begin{array}{l}\text { The PLA Information Engineering } \\
\text { University }\end{array}$ & 21 & 2.16 \\
\hline 8 & $\begin{array}{l}\text { China University of Mining and } \\
\text { Technology }\end{array}$ & 21 & 2.16 \\
\hline 9 & Nanjing University & 20 & 2.06 \\
\hline 10 & $\begin{array}{l}\text { Chengdu University of } \\
\text { Technology }\end{array}$ & 17 & 1.75 \\
\hline 11 & NanJing Normal University & 16 & 1.65 \\
\hline 12 & $\begin{array}{l}\text { Chinese Academy of Surveying } \\
\text { and Mapping }\end{array}$ & 13 & 1.34 \\
\hline 13 & AGRS & 13 & 1.34 \\
\hline Subtotal: & 41.22 \\
\hline $7 a b$ & 3. Instituts of highy cited & 2014 \\
\hline
\end{tabular}

Table 3. Institutions of highly cited papers from 2010 to 2014

\section{HIGH FREQUENCY KEYWORD ANALYSIS}

Keywords reflect the core content of the research results. Keyword frequency directly represents the amount of literatures on a certain subject, and indirectly reflects the focus of a discipline (Li and Yang 2004; Li et al. 2012). This paper analyzed 51,149 keywords published by 16 professional academic journals in the field of surveying and mapping from January 2010 to December 2014. By high frequency keyword, the progress and prospect of China's remote sensing technology during the past five years were further explored and revealed.

\subsection{Strategy of Keyword Pre-processing}

Besides remote sensing, 16 journals used in this research cover other aspects of surveying and mapping, and also the subjects including automation technology, computer applications, etc. By keyword selection, keywords with the accumulated frequency rank top 40 in each year were selected for research. And insubstantial keywords such as "Remote", "photogrammetry" and "analysis" were excluded. In addition, non-standard keywords were pre-processed. For example, "PS InSAR" and "PSInSAR" were processed as "PS-InSAR", "MATLAB", "Matlab" and "matlab" were regarded as one keyword. Moreover, differences brought by Chinese language were also considered. For example, some Chinese keywords look different. But when translated into English, they are the same. In this case, the keywords were incorporated into one.

\subsection{Hot Research Topics and Changes}

Through analysis of the annually accumulated frequency of keywords which rank top 40, we drew the conclusions listed as follows (because of the layout, the table on top 40 keywords of each year is omitted in this paper):

In recent years, keywords that continuously rank top 10 or so are "accuracy", "DEM", "remote sensing image", "hyperspectral”, "SAR", "LiDAR", “object-oriented", "MODIS", "NDVI", and "point cloud". The frequency of these words is high, reflecting the high degree of attentions to these academic topics. Accuracy analysis is the basis for remote sensing research, which is the foundation for all analysis in remote sensing. DEM describes ground elevation information. Since its wide use in national economy and defence construction, scholars performed extensive and in-depth discussions aiming its extraction and generation. Hyperspectral, SAR, and LiDAR has unique imaging characteristics and complementary mechanisms, respectively, which are the frontiers of remote sensing technology. LiDAR data processing is the processing to point clouds. Key techniques of objectoriented image analysis are image segmentation and multi-scale image analysis. We can see that the co-occurrence word frequency of "LiDAR" and "point cloud", as well as "objectoriented", "image segmentation" and "multi-scale" shows an increasing trend, which implies that they are the key research issues in remote sensing.

Keywords with relatively stable frequency are "land use", "application”, “classification”, "monitoring”, “information extraction", "feature extraction", "genetic algorithm”, "threedimensional modeling", "surface temperature”, etc. Frequency of these words does not increase very much while remaining top 40. The fields of study they representing are hot topics in recent years in remote sensing. Where, "land use", “application", "monitoring", and "surface temperature" reflect applications of remote sensing, and "classification”, "information extraction", "feature extraction", "genetic algorithm", and "threedimensional modeling” reflect image processing and analysis. 
As time goes by, keywords with gradually increased frequency are "high resolution", "data processing”, “deformation monitoring", "change detection", "UAV", and "land subsidence". It can be seen that they are always hot keywords and have drawn more and more attentions year by year. Highresolution is the inevitable trend of remote sensing development. With the rapid development, UAV technique will receive wide attentions in more fields. Research and applications of deformation monitoring and land subsidence based on SAR technology will be carried out more in-depthly. Especially, we can see that the frequency of "parallel computing" and "cloud computing" increases rapidly during the past three years, where the frequency number is 3 and 2 respectively in 2010, and 12 and 11 respectively in 2012. In 2012, the frequency number of the two keywords went into the top 40, and the ranking is rising in later years. Cloud computing and parallel computing of remote sensing data processing are the needs for development of data acquisition and rapid growth of remote sensing services, which provide new solutions for massive data storage, complex computing, and timeliness service. They are new research focuses in remote sensing, which represent the development trend of high-performance processing, and provide new opportunities for popularization of remote sensing technology and the establishment of business models of remote sensing.

In the high frequency keywords, there are keywords with frequency decreased as time goes by, which are "image fusion", "wavelet transform", "vegetation coverage", "support vector machine", "mixed pixel”, etc. Image fusion is the technique gradually developed since 1990s. It has considerably progressed during the past 20 years. Although its level of focus reduced from No. 4 in 2010 to No.15 in 2014, it is still an active keyword in the field of remote sensing. The reason for this phenomenon is the maturation of this technique, or maybe the waiting for a bigger breakthrough. Keywords "wavelet transform", "vegetation coverage", "support vector machine" and "mixed pixel" fell out of top 40 during the past three years, which means that the related research is no longer a hot topic in the field of remote sensing. Especially, "dynamic monitoring”, which was in top 40 in 2010, fell out of top 40 since 2011. "dynamic monitoring" mainly refers to the project of land use dynamic monitoring carried out in China since 1999. As this work was developed throughout China, the related techniques became mature, and it was not in top 40 since 2011.

In addition to above keywords, newly emerged high-frequency keywords are "geographic conditions”, "geographic conditions monitoring” and "geographic conditions census". Geographic conditions monitoring is a major national mapping project started in 2012 in China, which was given important instructions by Premier Keqiang Li. At the end of 2012, the pilot project of geographic conditions census was set out, and in 2014, this big project was carried out throughout China. Consistent with the time of this project, between 2010 and 2011, only keyword "geographic conditions monitoring” appeared twice; in 2012, "geographic conditions" and "geographic conditions monitoring” appeared several times and until 2013, "geographic conditions census" appeared. In 2014, related research began to be active and centralized, and "geographic conditions" and "geographic conditions census" jumped into top 5 high frequency keywords, and became hot topics that are very concerned.

\section{CONCLUSIONS}

This paper proposed a method by comprehensively using highly cited paper analysis and word frequency analysis together to analyze the research status and development trend of remote sensing in China. It studied periodical distribution, literature authors, research institutions, hot topics and development trend from the point of data acquisition, data processing and analysis, and remote sensing applications. Highly cited paper analysis and word frequency analysis has different characteristics and different views, which is complementary on subject progress analysis.

It can be seen that: with the advances of modern technology, the technology advancement of Chinese air-borne and space-borne remote sensing system continues to increase. In data acquisition phase, research focus is new civilian remote sensing satellite systems and UAV remote sensing system; research focus of data processing and analysis is multi-source information extraction and classification, laser point cloud data processing, objectoriented high resolution image analysis, SAR data and hyperspectral image processing, temporal data processing and change detection, etc., where, accuracy analysis goes through all aspects of data processing, and image fusion, support vector machine, mixed pixel and wavelet transform were paid less attentions to; development trend of remote sensing data processing is quantitative, intelligent, automated, and real-time, and the breadth and depth of remote sensing application is gradually increased; parallel computing, cloud computing and geographic conditions monitoring and census are the new research focuses to be paid attention to.

\section{REFERENCES}

LI De-ren, LIU Liang-ming, HU Xiao-qin, 2001. Development of photogrammetry and remote sensing in China from 1996 to 2000. ACTA GEODAETICA et CARTOGRAPHICA SINICA, 30(2), pp.117-126.

LIN Zong-jian, LI De-ren, XU Yan-Ying, 2011. General review on the new progress of earth observations. Science of Surveying and Mapping, 36(4): pp.5-8.

NING Jin-sheng, WANG Zheng-tao, 2014. Comprehensive report on development of 2012-2013 surveying and mapping. Science of Surveying and Mapping, 39(2): pp. 3-10.

NIE Lan-yin, 2012. Analysis of highly cited papers in orthopaedics in China. Chinese Journal of Scientific and Technical Periodicals, (4): pp.581-584.

LI Xiao-yang, 2014. Analysis of highly cited papers in chemistry from 2002 2012 in China. Chinese Journal of Scientific and Technical Periodicals, (1): pp.69-73.

LIANG Li-ming, XIE Cai-xia, 2003. Investigation of China's nanotechnology study based on frequency analysis of key words. Studies in Science of Science, (2): pp.138-142.

LI Wen-lan, YANG Zu-guo, 2004. Development in research subjects of library science in China judged by keyword frequency analysis. Library and Information Service, 48(12): pp.115-118.

CHEN Xi-min, DING Gui-peng, JIE Ya-li, et al., 2013. Output status of hot papers in international clinical research and 
The International Archives of the Photogrammetry, Remote Sensing and Spatial Information Sciences, Volume XL-7/W4, 2015 2015 International Workshop on Image and Data Fusion, 21 - 23 July 2015, Kona, Hawaii, USA

enlightenment to Chinese medical journals. Chinese Journal of Scientific and Technical Periodicals, (6): pp.1079-1084.

DING Zuo-qi, WANG Ming-hua, 2014. Hot paper analysis based on ESI in the field of botany and zoology and enlightenment to editors. Chinese Journal of Scientific and Technical Periodicals, (11): pp.1384-1390.

LI Jing, DONG Liang-guang, YOU Su-ning, 2012. Keyward analysis of Chinese Journal of Scientific and Technical Periodicals from 2006 to 2011. Chinese Journal of Scientific and Technical Periodicals, (3): pp.404-407. 